\title{
Challenges and Countermeasures of Regional Tourism Cooperation Development Strategy of Sichuan-Shanxi-Gansu Golden Triangle Area, Western China
}

\author{
Qin Jianxiong' ${ }^{1}$ Zhang Minmin ${ }^{1}$ \\ 1 College of tourism and historic culture, Southwest University For Natianalities, Chengdu, 610041
}

\begin{abstract}
SSGGTA triangle of three provinces, dependent landscape, folk customs are similar, for the first time since the 2002 held in Bazhong of SSGGTA triangle area tourism cooperation will be signed in SSGGTA triangle tourism, build "Golden Triangle" cooperation agreement, to 2005 has successively held 3 annual meeting. The goal of cooperation is through the sincere cooperation of the three provinces, the formation of regional tourism collaboration regular contact system, the characteristics of tourism products, the formation of regional joint promotion,a barrier free Tourism Zone, to realize the sustainable development of Shanxi tourism in Golden Triangle.
\end{abstract}

KEYWORDS: Golden Triangle Area;Regional;Tourism

\section{Introduction}

"Sichuan-Shanxi-Gansu Golden Triangle" ( so called SSGGTA) concept originated in 2000, was originally relates to tree provinces of West China i.e. Sichuan, Shanxi, and Gansu,. In 2002, held in Bazhong of SSGGTA triangle area tourism cooperation will be signed in SSGGTA triangle tourism, build "Golden Triangle" cooperation agreement, formal specification for Sichuan SSGGTA Golden Triangle Bazhong, Guangyuan, Dazhou and Shanxi Hanzhoung, Ankang three provinces and five municipalities region. Because the geological background of the formation of the SSGGTA Golden Triangle special, unique natural landscape and the humanities landscape. A $1000 \mathrm{~km}$ loop line between the tourist "Golden Triangle", visitors can explore in this line up and down five thousand years of culture, enjoy the mystery of Qinba landscape ${ }^{[1]}$. These tourism resources in Chongqing, Chengdu, Xi'an, Lanzhou, Wuhan five source among SSGGTA triangle tourism cooperation zone is composed of Sichuan Bazhong, Guangyuan, Dazhou and Shanxi Hanzhoung, Ankang three provinces and five municipalities, carry out cooperation in the past 3 years, three provinces and five municipalities in the propaganda, build mutual interaction, line group, strategic planning consensus interaction and so on has made significant progress, regional cooperation has been fully affirmed the two provincial government and support. Sichuan North Sichuan area has been the focus of tourism development in the province, tourism development, Shanxi will also Hanzhoung as the center to build ecological tourism. SSGGTA triangle tourism cooperation has achieved initial success ${ }^{[2]}$.

\section{Basis and conditions}

Golden Triangle is located in the Qin Chuan Shan (Ling) BA (Dabashan Mountain), connecting Bazhong Guangyuan - Lueyang - Baoji - Zhouzhi Fengxian Zhenan - Ankang - Wanyuan and other cities and counties area, like the Kawakita lock and key, connecting SSGGTA triangle three provinces bridge and the link, the guardian of Chuan Shan access, China's East-West watershed mountain ecological corridor and I in the southern and northern culture, our country's important north-south geographical dividing line, climate watershed and regional central "air conditioning", China come first on the list of biological diversity geographic treasure, 
become good ecological barrier in the upper reaches of the Yangtze river. The sweat, the Jialing River, canal river, Fujiang etc. originated in Qin Ba mountain area.

\section{Current situation and progresses}

3.1 the first stage: the framework, to lay the foundation

In 2002 February, Sichuan province takes the lead in SSGGTA triangle tourism cooperation signed a "framework" and the Shanxi Province, Guangyuan, Bazhong, Dazhou, Hanzhoung, Ankang five city tourism cooperation in SSGGTA triangle adjacent has taken substantial steps.

In 2002 April, Hanzhoung City, Nanchong City, Guangyuan City, Dazhou City, Bazhong City Tourism Bureau signed "SSGGTA triangle adjacent area tourism cooperation framework", "common good" and the "Three Kingdoms" hometown of two brands of Chuan Shan revolutionary base, build a barrier free Tourism Zone in Northeast sichuan.

the second stage: the establishment of area, promote cooperation

In 2002 October, Shanxi Chongqing Tourism "Golden Triangle first" regional cooperation will be held in Bazhong city. Three signed "Hanzhoung, Guangyuan, Bazhong tourism cooperation agreement", the joint development of $\mathrm{Ba}$ culture, culture of the Three Kingdoms, the Red Army Culture Tourism products.

3.3 the third stage: the in-depth cooperation, and seek common development

In 2004 July, SSGGTA triangle adjacent to the regional tourism cooperation forum will be held in Dazhou City, five city, to reach a consensus on a joint make Mikuni tourism, red tourism, ecotourism tourism products line three.

SSGGTA triangle tourism area large linkage, cooperation, big development, expand the SSGGTA Golden Triangle area tourism development space, improve the Nanchong, Guangyuan, Dazhou, Bazhong tourism is famous degree, promote the development of regional economy sustained rapid and healthy.

\section{Opportunities and Prospects}

4.1 the regional tourism cooperation has become a trend of the current tourism development

With the development of economic globalization and regional integration, among countries and regions of the personnel exchanges between the increasingly close, the flow of increasingly large scale, the world tourism development to the "no border tourism". "The opening of the market, the tourist to send each other, complementary advantages and win-win cooperation" as the principle of regional cooperation in tourism, has become a global consensus. Not only between countries, East Asian and Southeast Asian countries and regions have America Caribbean Tourism Cooperation as an important content of regional economic integration, the domestic Yangtze River Delta, Pearl River Delta region has also launched a new round of tourism cooperation in Yangtze River Delta, formed the climax, the Pan Pearl River Delta, Beijing metropolitan area tourism cooperation area, opened a new stage regional tourism cooperation in depth, and extended to the whole country. Chinese tourism in experienced three stages spot competition, city competition, line competition, a new era began to enter the regional collaboration and cross regional competition. Regional tourism cooperation, the depth and breadth are further expanding cooperation main body, more active, the level of cooperation is more rich, more comprehensive cooperation content.

\section{2 the National Tourism Administration is the} coordinated development of Tourism

With the regional economic integration process accelerating, take the "regional linkage, resource integration, complementary advantages and common development" road, become the main trend in the development of China's tourism industry, tourism industry also need to implement the "five balances" policy. National Tourism Bureau has been the important content of the coordinated development of tourism on the tourist industry of "eleven five" planning. 


\subsection{Chinese tourism market demand growth}

From 2005 to 2010, China per capita GDP development from the current $\$ 1000$ to $\$ 3000$, the proportion of people of medium income will increase from the current $18 \%$ to $40 \%$. The international statistical empirical data suggest that when a country's GDP per capita reached 800-1000 dollars, residents will generally produce domestic tourism motivation; to 400010000 dollars, will generate international tourism motivation. Visible, domestic and international tourism demand in China will be with China's economic development and sustainable growth.

4.4 two of the provincial government attaches great importance to the SSGGTA triangle tourism cooperation and development

Two, the provincial government attaches great importance to cooperation in tourism development in SSGGTA triangle, Sichuan Provincial People's Government in the "Implementation Opinions on accelerating the development of Sichuan tourism industry" ("opinion") region of SSGGTA triangle tourism cooperation will be listed one of the five major development area in Sichuan Province to speed up the development of tourism, at the same time, "opinions" clearly pointed out, should increase with the Shanxi joint development SSGGTA triangle Tourism Cooperation Zone dynamics, makes the region a new bright spot of tourism, and provides an important opportunity for the development of tourism in Northeast Sichuan area. The government of Shanxi province also has the SSGGTA triangle tourism "Golden Triangle" publicity listed as one of the three domestic tourism promotion activities in the province.

4.5 "11.5" province tourism planning attach great importance to tourism development in Northeast Sichuan area

The ecological and cultural tourism area of Jialing River Basin is one of the new boutique five tourism in Sichuan province. The plate of the Jialing River Basin and East Sichuan Dabashan Mountain Tourism plate as Sichuan tourism development framework and the focus of the layout of one of the five major tourism board. The Three Kingdoms culture tourism link Sichuan Province as one of the four major international tourist routes. Put forward the construction of Nanjiang Guangwu mountain, Tongjiang Connaught River scenic area, Guangyuan
Tangjiahe Nature Reserve, Xuanhan Bai Lixia District of ecological tourism, red tourism in SSGGTA triangle revolutionary base area, a great man hometown red tourist area, the Jialing River Basin in the cultural and ecological tourism zone, and eight in Taishan, calyx mountain, gorge in the tourism the scenic area.

4.6 in 2006 fourth session of the annual meeting of the SSGGTA triangle tourism cooperation

In 2006 fourth session of Shanxi tourism cooperation annual meeting was successfully held in Guangyuan City, held at the same time, the "Millennium Shudao tourism products promotion and project investment will". The collaboration will be aimed at strengthening the SSGGTA triangle tourism development through cooperation, connect the dots, string into a network, and actively promote the construction of scenic spot, strengthen in the protection of resources, tourism and culture, economic exchange, cooperation, to jointly build the SSGGTA Golden Triangle tourism brand, enhance the tourism image of Sichuan area, implementation will have a positive impact of tourism rapid economic growth.

\section{Problems and challenges}

\section{1 lack of tourism unified planning and less product development level}

SSGGTA triangle lack of tourism products unified line planning, tourism product exploitation repetition, low grades, the lack of leading tourism product line. Tourism product structure is single, in tourism is given priority to, not enough on its own characteristics, mining culture ecological environment, leisure and other characteristics and advantages. Tourism market structure imbalance, to local residents and regional market, the domestic market and entry market low proportion of remote.

\section{2 tourism elements don't match, the tourism} industry with low maturity

Tourism infrastructure especially can enter the condition difference, regional traffic conditions, traffic service facilities backward, travel between towns, tourist attractions, travel between towns and scenic spots between the backward transportation; tourism town backward function, service facilities should upgrade, tourism brand is yet to be set up; tourism enterprises, scattered, weak, poor small, lack of market 
competitiveness, enterprise resource should be integrated to form a system upgrade; development, production, marketing of tourism commodities; scenic spot development foundation is poor, tourist accommodation, catering, entertainment, shopping, conference, exhibition and other service facilities function needs improving; interaction aspect not formed between tourism industry and other industries, the tourism industry with low maturity.

\section{3 lack of investment in tourism marketing promotion}

SSGGTA triangle in poor and rural economy owes the developed area, lack of tourism product development funding, failure to form a unified planning and development situation, creating tourism brand of quantity is small, the lack of overall planning and long-term marketing plan, did not establish the unique overall tourism image, tourism line packaging promotion is not enough, inadequate publicity and promotion investment, the lack of high-quality marketing talents and a sound marketing system.

5.4 in the district cooperation breakthrough, areas of cooperation to be strengthened

The first is the foreign cooperation needs to be strengthened, SSGGTA triangle and surrounding provinces tourism cooperation has achieved a certain foundation, but in resource integration, complementary advantages, promote sales, market share and so on, limited cooperation depth and strength. Secondly, SSGGTA triangle five city is between the internal cooperation breakthrough, especially the lack of the mechanism of regional tourism products planning and co-ordination development, promote the tourism industry overall, comprehensive effect on regional economy has not fully played out.

5.5 intense tourist market competition, warm and cold development of tourism situation

SSGGTA triangle surrounding tourism scenic spots rich, high grade, high impact, a world natural heritage, the world cultural heritage Mausoleum of the First Qin Emperor, Jiuzhaigou Terracotta Army, Gansu Mogao
Grottoes, Chongqing scenery of the Three Gorges, Qingchengshan - Dujiangyan and other world famous product line. Therefore, how to highlight the area characteristics and advantages in the fierce competition in the tourism market, realize win-win cooperation, complementary advantages and the surrounding area, breaking the district tourism warm cold situation, is the most important challenge facing the development of the SSGGTA Golden Triangle.

\section{Cooperation principle and contents}

\section{1 the principle of cooperation}

Follow the "principle of regional linkage, resource integration, complementary advantages, common development", to strengthen the Sichuan, Shanxi linkage, joint development of the Three Kingdoms culture, red culture, Qinba landscape tourism, construction area of Golden Triangle Shanxi tourism cooperation. To create the characteristics of tourism products, the formation of regional joint promotion, build a barrier free tourism zone.

\section{2 the content of cooperation}

(1) interoperability information delivery. Improve once every year regularly contact system, refine the direction of cooperation, improve the interoperability information delivery channels, establish and improve the daily information passed each other contact mechanism.

(2) line mutual construction. Regional joint for attention to Sichuan, Shanxi province plans to finance, two, traffic, construction, electricity, communications, tourism, cultural and other departments, and actively strive for the national financial investment, accelerate the development and construction of Golden Triangle tourism scenic spots, to create the domestic and foreign well-known tourism gold line.

(3) propaganda interaction. The establishment of mutual, interactive advertising system, mutual cooperation area of publicity materials of tourism communication between scenic spots, hotels, departments, tourism scenic spot propaganda introduced to each other, sharing regional television, networks, newspapers and other news media resources, extend propaganda perspective, rich propaganda form, select the appropriate time, free publicity, tourism cooperation zone. 
(4) work mutual aid. Common area maintenance cooperation benefit, take effective measures to protect the cultural relics and ecological environment together, hand in hand cooperation in dealing with the upstream water quality, the surrounding environmental protection aspects of the overall situation, building the big tourism environment. To provide each other with promotion of convenience, organize regular hotel, scenic spots, tourist guide, tourism commodity production industries such as learning activities.

(5) group of reciprocity. Cooperative area travel agency to jointly launched the tourism line scenic spots area; area tourist units reception will give area travel agencies to provide more preferential policies, the travel agency, the scenic area between mutual actively recommend to the tourists resources and line, to reach the source to send each other, benefit sharing.

\section{Countermeasures}

7.1 the establishment of SSGGTA triangle Tourism Development Guidance Group

The establishment of "Chuan Shan Golden Triangle tourism development guidance", responsible for the coordination and guidance of Chuan Shan of Golden Triangle tourism development. Be responsible for coordinating the relationship between the various regions, departments.

\subsection{SSGGTA triangle Tourism Development Forum}

The establishment of "Chuan Shan Golden Triangle Tourism Development Forum", for the three provinces and five municipalities exchanges, coordination and cooperation to provide a dialogue platform. From Guangyuan, Hanzhoung, Bazhong, Ankang, Dazhou to rotate as the Secretariat, specifically around once a year round robin "Chuan Shan Golden Triangle tourism development forum".

\section{3 strengthen the tourism planning and management}

"Golden Triangle in SSGGTA triangle tourism development under the guidance of the steering group", and jointly promote the implementation and operation of "overall planning" and "Golden Triangle tourism development in SSGGTA triangle SSGGTA Golden Triangle tourism products and line planning". The relevant municipalities, county should develop around the tourism planning to deepen and implement.

The relevant planning SSGGTA Golden Triangle all relates to tourism activities, tourism industry, to coordinate with the "overall planning" and "Chuan Shan Chuan Shan Golden Triangle tourism development of Golden Triangle's tourism products and line planning". Various types of tourism planning and other planning should pay attention to the particular city planning, land use planning, the eco city (county, district) connection construction planning and related special planning.

\section{4 innovation of tourism investment and financing} mechanism

Adhere to government led, enterprise main body, market operation principle, actively guide social capital to participate in the tourism investment and financing diversified.

\section{5 the implementation of regional marketing strategy}

The relevant governments should break administrative boundaries, the implementation of the construction of barrier free Tourism Zone, through joint development, design, packaging tourist routes, accelerate connection grid each scenic quality and gold lines, support, coordinate and participate in each other in organizing tourist festivals, jointly carried out home and abroad and series of tourism market promotions, realize the sharing of resources, tourist market share, sharing and superposition advantages, to create a win-win situation in the development of tourism.

\section{6 strengthen the cultivation of tourism talents}

The introduction of tourism enterprise management and industry management personnel. Special attention should be paid to the introduction of tourism management, from the main target market of project planning, image promotion and other aspects of the senior management personnel.

To strengthen the cultivation of tourism talents, carry out various forms of tourism practitioners and the public quality training, academic and technical qualification training of employees, and actively introducing high-level management personnel, improve service level. 
Raise public awareness of tourism services, to create tourist soft environment, courtesy, enthusiasm and orderly.

7.7 strengthen the protection of resources and the environment

Combined with the protection of natural forests, returning farmland to forest project and ecological afforestation, strengthening the SSGGTA Golden Triangle natural tourism resources and cultural tourism resources protection. Do a good job of environmental impact assessment, to ensure that the construction of tourism infrastructure in harmony with the natural landscape. Formulate and improve policies and measures, establish a long-term mechanism of ecological construction.

\section{Conclusions and Perspective}

Analyzing the tourism development foundation, present situation, prospect and problems of opportunities, challenges based on the proposed

Golden Triangle, Sichuan and Shanxi tourism cooperation strategy and countermeasures.

Key words: regional tourism cooperation; Sichuan-Shanxi-Gansu Golden Triangle area(SSGGTA); Qin-Ba mountains

\section{Acknowledgements}

This paper is supported by"academic degrees construction subject of College of History and Culture, Southwest Universities of Nationalities(2012XWD-S1202)" and By the construction funds of research direction of " eco-tourism and resource economics research in ethnic areas of China, doctoral point of "China minority economics" Southwest University for Nationalities(2015-XWD-B0304)

\section{References}

[1]Qin Jianxiong, Zhang Pei, Deng Guiping,Chen Lu. $\underline{A}$ Study on Rural-Tourism and Sustainable Development of Economic Underdevelopment Areas-An Example from

Kanas Nature Reserve, Xingjiang Province, Northwest China. Smart Grid and Renewable Energy, 2014.6(16):170-179.

[2]Qin Jianxiong, Deng Guiping,Tang Yong. Discussions on the Rural-tourism Development of the Kanas Nature Reserve in Xinjiang, North-western China. in: Integrated Management of Low-carbon Economy \& Smart Scenic Area Information, Science Press, Beijing, 28 April, 2012, P.259-269. 